\title{
Actinic keratoses and basal and squamous cell carcinomas in elderly people: clinical aspects
}

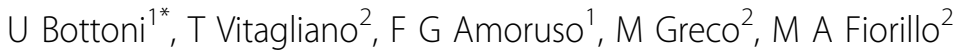 \\ From de Senectute: Age and Health Forum \\ Catanzaro, Italy. 5-7 December 2009
}

\section{Background}

Neoplastic skin alterations are frequently seen in elderly Caucasian people, above all if they have worked for long periods under high UV exposure. Our region, Calabria, a peninsula in the south of Italy with a long coastline , is quite homogeneous for population and lifestyle. Its inhabitants are Caucasian, most dark skinned but some fair skinned. Elderly people generally refer to a history of working as fishermen or farmers and consequently they have been exposed to the sun rays for long periods.

These facts explain the high incidence of basal cell carcinoma (BCC), squamous cell carcinoma (SCC) and actinic keratosis (AK) in our region, namely in elderly people.

\section{Materials and methods}

$\mathrm{BCC}$ and SCC are the most frequent malignant tumors that can be seen on the skin and consequently in the whole body. A fundamental step is the clinical suspicion. Regarding this issue, BCC as well as SCC and AK can present several different clinical aspects.

BCC may be nodular, pigmented, cystic, superficial, morpheaform, or may appear as a "rodent ulcer", also known as a "Jacobi ulcer". All of these subtypes present different biological behaviour: for instance, while superficial $\mathrm{BCC}$ is quite benign in its evolution, morpheaforme $\mathrm{BCC}$ or rodent ulcer are very aggressive and invasive. Pigmented BCC is cured by surgical excision, but it may be misdiagnosed with a nodular melanoma, that is a very aggressive disease.

SCC is generally distinguished in invasive SCC or SCC in situ. SCC in situ include Bowen's disease, erythroplasia of Queyrat in the penis and according to several authors also AK.

Invasive SCC presents a keratotic firm papule or plaque arising on sun-exposed skin. The color varies form pink to flesh colored to grey. Very characteristic are the surface change that include scaling, ulceration, crusting or the presence of a cutaneous horn.

AK is frequently the precursor of SCC. Therefore it has been considered by some authors as a precancer or a preneoplastic lesion, whereas other authors regard it as a true carcinoma in situ.

AK begins as a small macule, ill-defined, with dry, adherent scales, rough on the surface so that it can be felt more easily than seen. The color varies from skincolored to pink to red to brown. Lesions are frequently multiple and their size varies from few millimeters to 12 centimeters. AKs are often associated with other suninduced lesions such as solar lentigo, telangiectasia and solar elastosis.

Several clinical variants of AK are recognized: hypertrophic, lichenoid, proliferative, pigmented AK. Actinic cheilitis is considered a form sited on the lips.

\section{Conclusions}

Generally BCC and SCC are cured by thorough local excision. Unfortunately sometimes they can develop aggressive behaviour invading the surrounding and the underlying tissues. Therefore it is very important to diagnose them early before such invasiveness can appear.

\section{Author details}

1Department of Dermatology, University "Magna Graecia", Catanzaro, Italy. 2Department of Plastic Surgery, University "Magna Graecia", Catanzaro, Italy.

Published: 19 May 2010

doi:10.1186/1471-2318-10-S1-L31

Cite this article as: Bottoni et al:: Actinic keratoses and basal and squamous cell carcinomas in elderly people: clinical aspects. BMC Geriatrics 2010 10(Suppl 1):L31.

"Department of Dermatology, University "Magna Graecia", Catanzaro, Italy 